\title{
Obesity, but not hypohydration, mediates changes in mental task load during passive heating in females
}

\author{
Aaron R Caldwell ${ }^{1}$ ， Jenna Burchfield ${ }^{1}$, Nicole E Moyen ${ }^{1}$, Matthew A Tucker ${ }^{1,2}$, Cory L Butts ${ }^{1}$, R J Elbin ${ }^{1}$, \\ Matthew S Ganio ${ }^{\text {Corresp. } 1}$ \\ ${ }^{1}$ Exercise Science Research Center, University of Arkansas at Fayetteville, Fayetteville, AR, United States \\ 2 Georgia Prevention Institute, Augusta University, Augusta, GA, United States \\ Corresponding Author: Matthew S Ganio \\ Email address: msganio@uark.edu
}

Background. The independent effects of hypohydration and hyperthermia on cognition, and mood is unclear since the two stresses often confound each other. Further, it is unknown if obese individuals have the same impairments during hyperthermia and hypohydration that is often observed in non-obese individuals. Methods: The current study was designed to assess the independent and combined effects of mild hypohydration and hyperthermia on cognition, mood, and mental task load in obese and non-obese females. Twenty-one healthy females participated in two passive heating trials, wherein they were either euhydrated or hypohydrated prior to and throughout passive heating. Cognition (ImPACT), mental task load (NASA-TLX), and mood (Brunel Mood Scale; BRUMS) were measured before and after a $1.0^{\circ} \mathrm{C}$ increase in core temperature $\left(T_{C}\right)$.

Results. After a $1.0^{\circ} \mathrm{C} \mathrm{T}_{\mathrm{c}}$ elevation, hypohydration resulted in greater $(\mathrm{p}<0.05)$ body mass loss (-1.14 \pm 0.48 vs $-0.58 \pm 0.48 \mathrm{~kg}$ versus; hypohydrated and euhydrated, respectively) and elevation in serum osmolality $(292 \pm 4$ vs $282 \pm 3$ mOsm; $p<0.05)$ versus euhydration. Hypohydration, independent of hyperthermia, did not affect mental task load or mood $(p>0.05)$. Hyperthermia, regardless of hydration status, impaired ( 5 A.U) measures of memory-based cognition (verbal and visual memory), and increased mental task load, while worsening mood $(p<0.05)$. Interestingly, obese individuals had increased mental task load while hyperthermic compared to the non-obese individuals $(p<0.05)$ even while euhydrated. Hypohydration did not exacerbate any heat-related effects on cognition between obese and non-obese females ( $p>0.05)$. Conclusion. These data indicate that hyperthermia independently impairs memory-based aspects of cognitive performance, mental task load, and leads to a negative mood state. hypohydration did not exacerbate the effects of hyperthermia. However, obese individuals had increased mental task load during hyperthermia. 
1 Obesity, but not hypohydration, mediates changes in cognition and mental task load during 2 passive heating in females

3

4 Aaron R. Caldwell ${ }^{1}$, Jenna Burchfield ${ }^{1}$, Nicole E. Moyen ${ }^{1}$, Matthew A. Tucker ${ }^{1,2}$, Cory L. Butts ${ }^{1}$, 5 R. J. Elbin ${ }^{1}$, and Matthew S. Ganio ${ }^{1}$

$7{ }^{1}$ Exercise Science Research Center, University of Arkansas at Fayetteville, Fayetteville, AR, 8 United States

${ }^{2}$ Georgia Prevention Institute, Augusta University, Augusta, GA, United States

Address for Correspondence:

Matthew S. Ganio, Ph.D., FACSM

Exercise Science Research Center

University of Arkansas

155 Stadium Dr.

HPER 306-A

Fayetteville, AR 72701

Phone: 479-575-2857

Fax: 479-575-2853

msganio@uark.edu

Running Head: Hyperthermia, Hypohydration, and Obesity 


\section{Abstract}

28 Background. The independent effects of hypohydration and hyperthermia on cognition, and

29 mood is unclear since the two stresses often confound each other. Further, it is unknown if obese

30 individuals have the same impairments during hyperthermia and hypohydration that is often

31 observed in non-obese individuals. Methods: The current study was designed to assess the

32 independent and combined effects of mild hypohydration and hyperthermia on cognition, mood,

33 and mental task load in obese and non-obese females. Twenty-one healthy females participated

34 in two passive heating trials, wherein they were either euhydrated or hypohydrated prior to and

35 throughout passive heating. Cognition (ImPACT), mental task load (NASA-TLX), and mood

36 (Brunel Mood Scale; BRUMS) were measured before and after a $1.0^{\circ} \mathrm{C}$ increase in core

37 temperature $\left(\mathrm{T}_{\mathrm{C}}\right)$. Results. After a $1.0^{\circ} \mathrm{C} \mathrm{T}_{\mathrm{C}}$ elevation, hypohydration resulted in greater $(\mathrm{p}<0.05)$

38 body mass loss $(-1.14 \pm 0.48$ vs $-0.58 \pm 0.48 \mathrm{~kg}$ versus; hypohydrated and euhydrated, respectively)

39 and elevation in serum osmolality $(292 \pm 4$ vs $282 \pm 3 \mathrm{mOsm} ; \mathrm{p}<0.05)$ versus euhydration.

40 Hypohydration, independent of hyperthermia, did not affect mental task load or mood ( $\mathrm{p}>0.05)$.

41 Hyperthermia, regardless of hydration status, impaired ( 5 A.U) measures of memory-based

42 cognition (verbal and visual memory), and increased mental task load, while worsening mood

43 ( $\mathrm{p}<0.05)$. Interestingly, obese individuals had increased mental task load while hyperthermic

44 compared to the non-obese individuals $(\mathrm{p}<0.05)$ even while euhydrated. Hypohydration did not

45 exacerbate any heat-related effects on cognition between obese and non-obese females

46 ( $\mathrm{p}>0.05)$. Conclusion. These data indicate that hyperthermia independently impairs memory-

47 based aspects of cognitive performance, mental task load, and leads to a negative mood state.

48 hypohydration did not exacerbate the effects of hyperthermia. However, obese individuals had

49 increased mental task load during hyperthermia. 

occupational heat stress. These environments may cause hypohydration in addition to hyperthermia, resulting in decrements to physical and cognitive performance (Adam et al. 2008). serious implications for the safety of these workers. Therefore, understanding the independent and combined effects of hyperthermia and hypohydration on cognitive performance and mood may

57 provide valuable information for those individuals who live and work in warm environments.

Hypohydration is commonly induced with heat stress and/or exercise because the elevation in core temperature induces fluid loss secondary to sweating. However, both heat stress and exercise can independently affect cognition and mood (Tomporowski et al. 2007; Racinais et al. 2008). Therefore, a preferred methodology to independently examine the effect of hypohydration is fluid restriction. Some investigators have shown that mild hypohydration, with approximately 1-3\% body mass loss by fluid restriction, causes slower psychomotor processing speed, impaired visual and spatial working memory, increased errors and skill impairments (Wilson et al. 2003; Petri et al. 2006; Patel et al. 2007; Suhr et al. 2010; Smith et al. 2012; Lindseth et al. 2013). Additionally, mood ratings, such as feelings of tiredness and reduced vigor are observed with hypohydration (Shirreffs 2003; Szinnai et al. 2005; Patel, Mihalik et al. 2007; Pross et al. 2013). However, another study reported no cognitive differences with mild hypohydration ( 2\%) when fluid is restricted for 36-h (Szinnai, Schachinger et al. 2005). more precise measures of cognitive function such as visual processing, pattern recognition memory, and spatial memory (Wyon et al. 1979; Gaoua et al. 2011b). Simpler tasks like measures 
73 of attention are preserved (Gaoua, Racinais et al. 2011b). Many studies fail to report hydration

74 status and/or maintain euhydration. Therefore, the independent effect of heat stress, and thus

75 hyperthermia, is sometimes difficult to discern.

76 Increased body mass index (BMI) in healthy young individuals is correlated with impaired

77 executive function, attention, problem solving, memory, and mental flexibility (Gunstad et al.

78 2006; Gunstad et al. 2007; Fedor et al. 2013). Although there is a paucity of data with obese

79 individuals, some studies suggest obesity is linked with poorer cognitive performance compared

80 to lean controls (Boeka et al. 2008; Lokken et al. 2009; Lokken et al. 2010). Poor cognitive

81 performance may be exacerbated in obese individuals when heat stressed because of impaired

82 thermoregulatory control (Bar-Or et al. 1969; Buskirk et al. 1969; Tucker et al. 2017). However,

83 the independent and combined effects of hyperthermia and hypohydration on cognition and mood

84 in obese individuals have not been investigated. Obese individuals also appear to have alterations

85 in brain structure (Stanek et al. 2011) and function (Wolf et al. 2007) which may affect changes in

86 cognitive performance or mental task following certain stressors (Mehta 2015). Further, given one-

87 third of Americans are reported to be overweight or obese (Ogden et al. 2015), it is important to

88 understand how cognition and mood are effected when obese individuals are heat stressed and/or

89 hypohydrated.

90 Therefore, the purpose of this study was to examine the independent and combined effects

91 of mild hypohydration (i.e., $<2 \%$ body mass loss) and hyperthermia on cognition, mental task load,

92 and mood in obese and non-obese individuals. We chose rather mild levels of hypohydration and

93 hyperthermia because there is dearth of information in this area, but preliminary evidence suggests

94 that mild hypohydration and hyperthermia may have cognitive (Ganio et al. 2011; Armstrong et

95 al. 2012) and physiological (Moyen et al. 2016; Tucker et al. 2018) effects. Likewise, these mild 
96 levels are more likely to occur in everyday living. We hypothesized that mild hypohydration,

97 induced by 24-h of fluid restriction, and hyperthermia would impair cognition and increase the

98 mental effort necessary to complete a task, defined as mental task load (Hart et al. 1988).

99 Furthermore, we hypothesized that hypohydration would exacerbate hyperthermic-related

100 impairments. We also hypothesized that impairments would coincide with a worsening in mood

101 state (i.e. increased fatigue, lowered vigor, etc). Finally, we hypothesized that obese individuals

102 would have greater decrements both cognition, mental task load, and mood compared to non-obese 103 participants.

\section{MATERIALS AND METHODS}

105

Ten obese and 11 non-obese female adults from 18 to 35 years old from the University of

Arkansas and surrounding community were recruited for this study. A priori power calculations

were not performed prior to data collection, but post-hoc power can be estimated from the statistics

provided in the results. The University of Arkansas Institutional Review Board granted Ethical approval to carry out this study within its facilities (IRB\# 14-05-719). Prior to participation all participants signed a written informed consent. Participants were excluded if they had a history of any diseases that could affect body fluid balance, or if they had a history of psychiatric disease, concussion, dyslexia, or attention-deficit/hyperactivity disorder. This study focused on female participants considering the paucity of data within this population. Furthermore, participants were excluded if they took drugs influencing body fluid balance (e.g., diuretics) or regularly consumed

115 the caffeine equivalent of greater than six cups of coffee each day. Those who had an irregular 116 menstrual cycle, as well as those using an intrauterine device, or progesterone only form of birth 117 control were excluded due to different hormone concentrations of estrogen and progesterone from 118 normally menstruating females. Participant characteristics are in Table 1. 


\section{Experimental Design}

120 A randomized, repeated-measures design was used to determine the independent and

121 combined effects of hypohydration and hyperthermia on cognitive performance, mental task load,

122 and mood. Each participant completed a familiarization and two trials: one euhydrated and one

123 hypohydrated. The familiarization visit occurred within two weeks prior to the first trial. Before

124 each trial, participants participated in a 24-h hydration intervention (described below) before

125 having their core temperature increased $1.0^{\circ} \mathrm{C}$ via passive heating. Trials occurred during the

126 follicular phase of the menstrual cycle (days 1-7). Menstrual cycle status was based on self-

127 reported start of menses. A minimum of 48-h. separated trials. The layout of each trial is in Figure 1281.

\section{INSERT FIGURE 1 HERE}

130

131

132

133

134

135

136

137

138

139

140

141

\section{Measures}

Brunel Mood Scale (BRUMS). BRUMS is validated instrument, derived from the Profile of Mood States, with 24-item Likert measures evaluating feelings of tension, depression, anger, vigor, fatigue, and confusion (Terry et al. 1999). The Likert type items ask respondents to indicate the extent to which they are experiencing these feelings. Items are anchored by " $0=$ Not at all", and " $4=$ Extremely". The reference timeframe utilized was "How you feel right now".

Immediate Post-Concussion Assessment and Cognitive Testing (ImPACT). ImPACT computerized neurocognitive test evaluates performance by measuring six neurocognitive modules that assess memory, attention learning, processing speed and reaction time. Scores are created from the six neurocognitive modules that yield four composite scores; verbal memory, visual memory, visual motor processing speed, and reaction time in seconds. The ImPACT baseline test is a stable measure of neurocognitive performance and minimizes practice effects 
142 through the use of multiple versions. ImPACT provides randomization of stimuli in alternate forms

143 at the initial test session and all subsequent test sessions included different forms to minimize

144 practice effects. Overall, current evidence would indicate that the ImPACT does adequately

145 control for practice effects (Schatz et al. 2006).

146 Mental Task Load. A visual analog scale (VAS) of concentration and the NASA Task Load

147 (NASA-TLX) were utilized to quantify mental task load (Hart and Staveland 1988; Bijur et al.

148 2001). The VAS is a continuous scale with two extreme statements used as anchors at opposite

149 ends of a $100 \mathrm{~mm}$ line. The anchors used were "not at all strong(ly)" and "very strong(ly)". This

150 scale was used to assess concentration using the statement "How hard did you have to concentrate

151 to accomplish the tasks successfully?". The NASA-TLX utilized in this study measured subjective

152 workload for mental demands, temporal demands, mental performance, effort, and frustration. The

153 participant marks on a line, which represents a continuous scale for each of the previously

154 mentioned sub-scales.

155

Measures of Hydration Status. Four measures of hydration status were utilized in each experimental trial: body mass change, serum osmolality $\left(\mathrm{S}_{\mathrm{OSM}}\right)$, urine osmolality $\left(\mathrm{U}_{\mathrm{OSM}}\right)$, and urine

157 specific gravity $\left(\mathrm{U}_{\mathrm{SG}}\right)$.

Change in body mass was calculated from the baseline weight recorded as the average of

159 the three or more weights obtained by the participant as follows. Participants were sent home with 160 a scale (Model: IP-TITN-ZJXR, BalanceFrom) to record nude body weight at the same time, 161 relative to the start time of their trials, each day for three consecutive days to establish a baseline 162 body weight (Cheuvront et al. 2004). From this baseline, body weight, the amount of body mass 163 lost, or gained, during the 24-h hydration intervention (see below) was calculated. The percentage 164 of body weight change from baseline was used to determine percent hypohydration at the 
165 beginning of each trial (i.e., before heating but after the 24-h hydration intervention) and after each 166 trial (i.e., after heating).

$167 \mathrm{U}_{\mathrm{SG}}$ was measured via a refractometer (clinical refractometer 30005, SPER Scientific,

168 Scottsdale, AZ, USA). $\mathrm{U}_{\mathrm{OSM}}$ and $\mathrm{S}_{\mathrm{OSM}}$ were measured by freezing point depression (3D3

169 Advanced Instruments Osmometer, Model 3250, Norwood, MA, USA).

170 Previously determined cutoffs for body mass change $(<1 \%), \mathrm{S}_{\mathrm{OSM}}(<290 \mathrm{mOsm}), \mathrm{U}_{\mathrm{OSM}}$

$171(<700 \mathrm{mOsm})$, and $\mathrm{U}_{\mathrm{SG}}(<1.020)$ were used to define participants as euhydrated and participants

172 were required to meet three of the four criteria prior to starting a trial (Sawka et al. 2007).

173 Thermal Measurements. Skin temperature $\left(\mathrm{T}_{\mathrm{sk}}\right)$ was measured via skin thermocouples

174 (Omega Engineering, Stamford, CT, USA) placed on the right anterior thigh (midway between the

175 greater trochanter and lateral condyle), chest (midway between the axilla and areola), lateral calf

176 (midway between the tibial condyle and malleolus), and upper arm. Mean-weighted $\mathrm{T}_{\mathrm{sk}}$ was

177 calculated according to Ramanathan (Ramanathan 1964): $\mathrm{T}_{\mathrm{sk}}=0.3(\mathrm{chest}+\operatorname{arm})+0.2($ thigh + 178 calf). A rectal thermister (Physitemp Inc., Clifton, NJ, Ret-1) was used to measure core 179 temperature $\left(\mathrm{T}_{\mathrm{C}}\right)$. Mean body temperature $\left(\mathrm{T}_{\mathrm{b}}\right)$ was calculated using $\mathrm{T}_{\mathrm{C}}$ and $\mathrm{T}_{\mathrm{sk}}(19): \mathrm{T}_{\mathrm{b}}=0.2\left(\mathrm{~T}_{\mathrm{sk}}\right)$ $180+0.8\left(\mathrm{~T}_{\mathrm{C}}\right)$

\section{Familiarization}

182

Prior to experimental trials, participants underwent a familiarization visit. At this visit we

183 recorded the participant's body mass via a scale (Health-o-Meter ${ }^{\circledR}$ digital scale, model: 349KLX,

184 IL, USA), height via a stadiometer (Seca, model: 7701321004, Vogel \& Hamburg, Germany), and 185 body composition via dual x-ray absorptiometry (DXA, General Electric ${ }^{\circledR}$, Lunar Prodigy Promo).

186 Participants were classified as lean if their body fat was $<32 \%$ whereas a body fat of $>39 \%$ was 187 classified as obese (Gallagher et al. 2000). 

concentration, and the NASA-TLX. Participants were sent home with a scale to establish a baseline

190 body weight as described above (Cheuvront, Carter et al. 2004).

\section{Experimental Trials}

194 (i.e., calories) for the subsequent trial. During the euhydrated trial participants were encouraged to 195 consume adequate fluid, including an extra $950 \mathrm{ml}$ the night prior to the trial and $475 \mathrm{ml} \sim 2$ hours 196 before the trial. Also, during passive heating for the euhydrated trial, participants consumed $37.5^{\circ} \mathrm{C}$ 197 water to maintain euhydration. For the hypohydrated trial participants were given a $250 \mathrm{ml}$ bottle 198 of water and asked to refrain from all other fluids and high moisture content foods (e.g., soup and 199 fruits) for the 24-h prior to laboratory arrival. Furthermore, no fluid was ingested throughout 200 passive heating.

201 Prior to each experimental trial participants refrained from alcohol and exercise for 24-h, 202 food for 4-h, and caffeine for 8-h. After the 24-h fluid intervention, and upon arrival to the 203 laboratory, pre-test compliance was verified with a 24-h history questionnaire. Participants then 204 used a private bathroom to obtain a nude weight (Health-o-Meter® digital scale, model: 349KLX, 205 IL, USA), insert a rectal thermistor, and provide a urine sample for measures of $\mathrm{U}_{\mathrm{SG}}$ and $\mathrm{U}_{\mathrm{OSM}}$. 206 Participants were then fitted with a blood pressure cuff (Tango+; SunTech Medical, Inc., 207 Morrisville, NC, USA) placed directly over the brachial artery to obtain blood pressure via 208 electrosphygmomanometry, and a monitor around the chest continuously recording heart rate (HR; 209 Polar Electro Inc., Lake Success, NY, USA). Skin thermocouples were then placed on the 210 appropriate locations (see above). 
212 body, except the head, face, hands, and feet (Allen-Vanguard Technologies, Ottawa, Canada). The

213 suit permits the control of $\mathrm{T}_{\mathrm{SK}}$ and $\mathrm{T}_{\mathrm{C}}$ temperature by changing the temperature of the water

214 perfusing the suit. After instrumentation, and prior to heating, participants completed BRUMS

215 mood assessment, ImPACT and mental task load measures (VAS and NASA-TLX). Then an

216 intravenous catheter was inserted into the antecubital vein. After participants laid supine for $\sim 30$

217 minutes a blood draw was obtained. During the resting period water at $34^{\circ} \mathrm{C}$ was perfused through

218 the suit. After this resting period, participants were then exposed to passive heat stress by perfusing

$21945^{\circ} \mathrm{C}$ water through the suit and moved into an environmental chamber $\left(34.5 \pm 0.6^{\circ} \mathrm{C}, 30.8 \pm 0.9 \%\right.$

220 relative humidity). $\mathrm{HR}, \mathrm{T}_{\mathrm{SK}}, \mathrm{T}_{\mathrm{B}}$ and $\mathrm{T}_{\mathrm{C}}$ were continuously measured via computer software

221 (LabChart7, Colorado Springs, CO). Once a $1.0^{\circ} \mathrm{C} \mathrm{T}_{\mathrm{C}}$ increase was achieved, $\mathrm{T}_{\mathrm{C}}$ was maintained

222 at this temperature by stabilizing the temperature of the water going through the suit. At the $1.0^{\circ} \mathrm{C}$

223 increase in $\mathrm{T}_{\mathrm{C}}$, a blood draw was obtained. Participants then completed the BRUMS mood

224 assessment, ImPACT cognitive test and mental task load measures (VAS and NASA-TLX). All

225 ImPACT test sessions included different forms to minimize practice effects. Once testing was

226 completed, nude body mass, to calculate total body water loss, was obtained and participants

227 provided another urine sample.

228 Statistical Analysis

229 Statistical analyses were performed using IBM SPSS Statistics v23. In order to establish

230 evidence for the experimental design, a series of separate univariate ANOVAs were performed for

231 all physiological $\left(\mathrm{T}_{\mathrm{C}}, \mathrm{T}_{\mathrm{B}}, \mathrm{T}_{\mathrm{SK}}, \mathrm{HR}\right)$, hydration $\left(\mathrm{U}_{\mathrm{SG}}, \mathrm{U}_{\mathrm{OSM}}, \mathrm{S}_{\mathrm{OSM}}\right.$, and body mass change) variables.

232 In order to test our hypotheses, three 2 (hypohydrated vs euhydrated) by 2 (baseline vs

233 hyperthermia) by 2 (obese vs non-obese) multivariate repeated measures analysis of variance 
234 (MANOVAs) were performed on cognitive performance, mental task load, and mood outcome

235 variables. Cognitive performance outcome scores were derived from the ImPACT battery and

236 included verbal memory, visual memory, processing speed, and reaction time. Mental task load

237 scores were derived from the NASA-TLX and VAS and included mental demands, temporal

238 demands, mental performance, effort and frustration, and concentration. Mood scores were derived

239 from the BRUMS and included tension, depression, anger, vigor, fatigue, and confusion.

240 An alpha of less than 0.05 was deemed significant. In the case of a multivariate alpha of

241 less than 0.10 an exploratory analysis of the univariate effects were performed. If a statistically

242 significant multivariate effect was identified, then corresponding univariate ANOVAs were

243 examined.

244

\section{RESULTS}

\section{Confirmation of Experimental Design}

246

Hydration. Overall, there were no differences between hydration variables in the obese and

247 non-obese groups. In the euhydrated trial, subjects arrived with a body mass loss of only $0.02 \pm$

$2481.19 \%$ (relative to 3 -day euhydrated baseline body mass), a $\mathrm{S}_{\mathrm{OSM}}$ of $283 \pm 2 \mathrm{mOsm}$, U $\mathrm{USM}_{\mathrm{OSM}}$ of 331

$249 \pm 198 \mathrm{mOsm}$, and a $\mathrm{U}_{\mathrm{SG}}$ of $1.011 \pm 0.005 . \mathrm{S}_{\mathrm{OSM}}$ did not increase in the euhydrated trial with

250 hyperthermia (mean change: $-1.8 \mathrm{mOsm} \pm 3.5 ; \mathrm{p}=0.01$ ). There was a small change in body mass

251 (mean change: $-0.64 \pm 0.56 \% ; \mathrm{p}=0.05$ ). $\mathrm{U}_{\mathrm{OSM}}$ and $\mathrm{U}_{\mathrm{SG}}$ increased slightly after hyperthermia

252 during the euhydrated trial (mean change: $52 \pm 199$ mOsm and $0.003 \pm 0.006$, respectively;

$253 \mathrm{p}>0.05$ ). However, participants were still considered euhydrated by current guidelines (Armstrong 254 2007).

255 In the hypohydrated trial, percent body mass loss $(-1.06 \pm 0.80 \%), \mathrm{S}_{\mathrm{OSM}}(287 \pm 3 \mathrm{mOsm})$, $256 \mathrm{U}_{\mathrm{OSM}}(986 \pm 118 \mathrm{mOsm})$, and $\mathrm{U}_{\mathrm{SG}}(1.025 \pm 0.004)$ were all elevated relative to the euhydrated trial 
257 (all $\mathrm{p}<0.01$ ). During the hypohydrated trial, body mass, $\mathrm{U}_{\mathrm{OSM}}, \mathrm{U}_{\mathrm{SG}}$, and $\mathrm{S}_{\mathrm{OSM}}$ changed with passive

258 heating $(-1.15 \pm 0.45 \%, 53 \pm 50 \mathrm{mOsm}, 0.002 \pm 0.003$, and $-4.8 \pm 2.7 \mathrm{mOsm}$, respectively; all

$259 \mathrm{p}<0.05)$. When hyperthermic and hypohydrated, $\mathrm{U}_{\mathrm{OSM}}, \mathrm{U}_{\mathrm{SG}}, \mathrm{S}_{\mathrm{OSM}}$, and body mass loss were greater

260 compared to euhydrated and hyperthermic (all $\mathrm{p}<0.001$ ). Detailed hydration data are available in

261 in Table 2.

262 Physiological Responses. As expected, $\mathrm{T}_{\mathrm{C}}, \mathrm{T}_{\mathrm{SK}}$, and $\mathrm{T}_{\mathrm{B}}$ increased during hyperthermia

263 (mean change: $0.97 \pm 0.05^{\circ} \mathrm{C}, 2.65 \pm 1.00^{\circ} \mathrm{C}$, and $1.14 \pm 0.09^{\circ} \mathrm{C}$, respectively; all $\mathrm{p}<0.001$ ).

264 However, none of the other physiological variables (i.e., $\mathrm{T}_{\mathrm{C}}, \mathrm{T}_{\mathrm{SK}}$, and $\mathrm{T}_{\mathrm{B}}$ ) were significantly

265 different between non-obese and obese groups in the euhydrated trial (all $\mathrm{p}>0.05$ ).

266 Hypohydration did not alter baseline $\mathrm{T}_{\mathrm{C}}, \mathrm{T}_{\mathrm{B}}$, or HR with the exception of $\mathrm{T}_{\mathrm{SK}}$ being higher

267 (mean difference: $0.37 \pm 0.54^{\circ} \mathrm{C} ; \mathrm{p}<0.01$; independent effect of hydration). HR was significantly

268 higher in obese compared to non-obese at baseline in the hypohydrated trial (mean difference: 10

$269 \pm 18 \mathrm{bpm} ; \mathrm{p}=0.02)$. Also, obese females had slightly higher HR after passive heating in the

270 hypohydrated trial (mean difference: $9 \pm 19 \mathrm{bpm} ; \mathrm{p}=0.04)$. There were no other differences in the

271 physiological variables (i.e., $\mathrm{T}_{\mathrm{C}}, \mathrm{T}_{\mathrm{SK}}$, and $\mathrm{T}_{\mathrm{B}}$ ) between non-obese and obese groups in the

272 hypohydrated trial (all $\mathrm{p}>0.10$ ).

273 In the hypohydrated trial, passive heating increased $\mathrm{T}_{\mathrm{C}} 0.99 \pm 0.02^{\circ} \mathrm{C}, \mathrm{T}_{\mathrm{SK}} 2.69 \pm 1.01^{\circ} \mathrm{C}$,

$274 \mathrm{~T}_{\mathrm{B}} 1.16 \pm 0.11^{\circ} \mathrm{C}$, and HR $32 \pm 8 \mathrm{bpm}($ all $\mathrm{p}<0.01) . \mathrm{T}_{\mathrm{SK}}$ and $\mathrm{T}_{\mathrm{B}}$ were greater at the end of the 275 hypohydrated trial compared to the euhydrated trial (mean difference: $0.40 \pm 0.69$ and $0.13 \pm$ $2760.23^{\circ} \mathrm{C}$, respectively; $\left.\mathrm{p}=0.01\right)$. $\mathrm{T}_{\mathrm{C}}$ did not differ between trials at the end of heating $(\mathrm{p}>0.05)$.

277 Detailed physiological data are available in Table 3.

\section{Testing of Hypotheses}


280 between hyperthermia, hydration, group obesity on cognitive performance $F(4,16)=1.31, \mathrm{p}=$ 2810.30 , Wilks' $\Lambda=0.25$ Also, there was not a two-way multivariate interaction between obesity and 282 hyperthermia, $F(4,16)=0.22, \mathrm{p}=0.92$, Wilks' $\Lambda=0.95$, or obesity and hydration $F(4,16)=0.20$, 283 $\mathrm{p}=0.92$, Wilks' $\Lambda=0.95$

Further, there was no multivariate interactions between hydration and hyperthermia, $F(4$, 285 $16)=1.53, p=0.24$, Wilks' $\Lambda=0.75$. However, there was an independent, multivariate effect of hyperthermia indicating a decrease in cognitive performance, $F(4,16)=3.01, \mathrm{p}=0.049$, Wilks' $\Lambda$ 287 $=0.57$. Follow-up univariate analyses, presented in Figure 2, indicated that hyperthermia leads to a reduction in verbal recognition memory, $F(1,19)=6.98, \mathrm{p}=0.02$, and trend towards reduction in visual working memory $F(1,19)=3.58, \mathrm{p}=0.07$, but no change in visual processing speed or reaction time. Further, there was trend towards an independent multivariate effect of hydration status $F(4,16)=2.68, \mathrm{p}=0.07$, Wilks' $\Lambda=0.59$. Follow-up univariate tests revealed that only visual working memory was slightly reduced when hypohydrated (mean change: $-4.9 \pm 1.8$ A.U., $\mathrm{p}=0.01)$

\section{INSERT FIGURE 2 ABOUT HERE} hyperthermia on mental task load $F(6,14)=0.74, \mathrm{p}=0.63$, Wilks' $\Lambda=0.24$. Further, there was not a multivariate interaction between obesity and hydration status $F(6,14)=1.164, \mathrm{p}=0.38$, Wilks' $\Lambda=0.67$. However, there was an interaction between obesity and hyperthermia $F(6,14)=$ 2.93, $\mathrm{p}=0.04$, Wilks' $\Lambda=0.44$. Interestingly, only in obese participants, hyperthermia increased mental demand $(p<0.04)$, decreased ratings of performance $(p<0.01)$, and increased effort $(p<0.01$;

301 Figure 3). Pairwise comparisons indicate that temporal demand and frustration were unaffected by 
302 hyperthermia in either group (Figure 3, Panel B and D; $>0.05$ ). In both obese and non-obese 303 participants concentration increased (Figure 3, Panel F; $<<0.05$ ).

304

305

306

307

308

309

310

312

314

315

316

317

318

319

320

321

322

323

324

\section{INSERT FIGURE 3 ABOUT HERE}

There was trend for a multivariate interaction between hydration status and hyperthermia, $F(6,14)=2.93, \mathrm{p}=0.06, \mathrm{Wilks}^{\prime} \Lambda=0.46$. Exploratory analysis of the univariate tests only revealed differences in temporal demand, which pairwise comparisons indicated a small but significant increase in temporal demand when hypohydrated (mean change: $5.5 \pm 9.1$ A.U.; $p<0.05$ ), but not when euhydrated (mean change: $1.3 \pm 7.5$ A.U.; $p=0.42$ ). Independent of hyperthermia, there was no multivariate effect of hypohydration, $F(6,14)=2.93, \mathrm{p}=0.29$, Wilks' $\Lambda=0.63$.

Mood State. There was no interaction between obesity, hydration, and hyperthermia, $F(6$, $14)=1.51, \mathrm{p}=0.25$, Wilks' $\Lambda=0.61$. Also, there was no interaction between hydration status, $F(6,14)=1.73, \mathrm{p}=0.19$, Wilks' $\Lambda=0.57$, or hyperthermia, $F(6,14)=0.74, \mathrm{p}=0.63$, Wilks' $\Lambda=$ 0.76 (i.e. non-significant interaction). Furthermore, there was no interaction between hydration and hyperthermia on $\operatorname{mood} F(6,14)=0.95, \mathrm{p}=0.49$, Wilks' $\Lambda=0.711$. Mood state did not appear to change when hydration status was altered, independent of hyperthermia, $F(6,14)=1.98, \mathrm{p}=$ 0.14 , Wilks' $\Lambda=0.54$.

However, there was trend for a main effect of hyperthermia $F(6,14)=2.79, \mathrm{p}=0.05$, Wilks' $\Lambda=0.46$. An exploratory univariate analysis, displayed in Figure 4, indicated increases in anger (mean change: $0.4 \pm 0.46$ A.U.; $<<0.01$ ) and depression (mean change: -0.9 A.U. \pm 1.1 ; $\mathrm{p}<0.01$ ), and decreased vigor (mean change: $-1.1 \pm 2.1$ A.U.; $p=0.03$ ) during hyperthermia. There were no changes in tension, fatigue, or confusion (all $\mathrm{p}>0.10$; Figure 4).

INSERT FIGURE 4 ABOUT HERE

\section{DISCUSSION}


In this study, we examined the independent and combined effects of mild hypohydration

326 and hyperthermia on cognition, mental task load, and mood between obese and non-obese females.

327 Mild hypohydration did not influence cognitive performance, mental task load, or mood state

328 regardless of hyperthermia or obesity. Hyperthermia, when observed separately from hydration

329 status (i.e. main effect of hyperthermia), decreased cognitive performance. In particular, measures

330 of verbal memory and visual memory were impaired, but reaction time and visual motor processing

331 were maintained. At the same time, most measures of mental task load (demand, performance,

332 effort, and concentration) were increased during hyperthermia. This analysis included obese and

333 non-obese individuals. Follow-up analysis revealed that much of the effect was driven by an

334 independent effect of the obese individuals having increased mental task load during hyperthermia;

335 for the most part, the non-obese individuals had no measurable change. Lastly, mood state, while

336 unaffected by obesity or hydration, was negatively affected by hyperthermia, which corresponded

337 to increased feelings of depression, anger, and reduced vigor. Overall, hyperthermia, but not

338 hypohydration, decreases cognitive performance, and worsens mood state in young females.

339 Mental task load specifically increased in obese females while hyperthermic; non-obese female's

340 mental task load was unaffected by hyperthermia.

341 The rationale for the current study stems Baar's global workspace theory of the conscious

342 mind which has a limited capacity (Baars 1993). Baar's suggests cognitive processes are working

343 in competition with each other rather than in parallel. Selected activities dominate cognitive

344 awareness by harnessing executive function. Stressors could increase the need for cognitive

345 function in one area of the brain, compromising other areas of the brain via cognitive load

346 competition (Cohen 1983; Baars 1993). In our study, hyperthermia impaired cognitive

347 performance while increasing perceived symptoms (thermal sensation) and impairing mood state. 
348 Therefore, competition surfaced in executive function, and in order to preserve the cognitive skill

349 being used, the brain exerts more effort toward the skills, sparing cognitive performance

350 impairment in reaction time and visual processing. Thus, in order to meet the demands for stable

351 cognitive performance, mental task load increases.

352 Effects of mild hypohydration

353

In the current study, cognitive function, mood state, and mental task load were preserved 354 with $1.1 \%$ hypohydration in both obese and non-obese females. Like in previous studies (Amos et al. 2000; Grego et al. 2005), the magnitude of hypohydration may not have been sufficient to induce an observable impairment in cognitive function. Theoretically, there is a threshold at which the mental task load becomes too great, leads to exhaustion, and cognitive function beings to decline. Young healthy participants are able to adapt to progressive water deficit, even up to $2.6 \%$ body mass loss, and maintain cognitive performance (Szinnai, Schachinger et al. 2005), which is in agreement with the current study. Kempton et al, suggest this phenomenon is fueled by the increase in the fronto-parietal brain activation resulting in unimpaired cognitive scores and a deteriorated mental task load (Kempton et al. 2011). During fluid restriction there may be an initial drop in short-term memory followed by a return to baseline 3.5 hours later, independent of rehydration (Cian et al. 2000; Szinnai, Schachinger et al. 2005). In our study, no changes in cognitive function during hypohydration, via ImPACT, were detected. Overall, cognitive function appear to be well-preserved with mild hypohydration during fluid restriction.

\section{Effects of hyperthermia}


371 to a lesser degree visual memory, were impaired (Figures $2 \& 3$ ). These visual and verbal memory

372 impairments are similar to those observed in previous studies (Gaoua, Racinais et al. 2011b;

373 Schlader et al. 2013). Cognitive function involving greater neuronal resources are impaired to a

374 greater extent during heat stress than less demanding tasks (Hocking et al. 2001; Simmons et al.

375 2008; Gaoua et al. 2011a; Gaoua, Racinais et al. 2011b; Schlader et al. 2015) and memory is a

376 more complex task than attention tasks. Baddedly's working memory theory states verbal memory

377 is controlled by the phonological loop, while the "visuospatial sketchpad" controls visual memory

378 (Baddeley et al. 1974). These functions are connected and controlled by central executive function.

379 In order to store memory as long-term memory, rehearsal is necessary, and visual memory is of

380 limited capacity. Therefore, if the brain is exerting effort toward storing verbal memory, which is

381 an easier task, competition occurs and the brain's ability to store visual memory, a more 382 complicated task, is limited.

383 Unlike memory, reaction time and attention were maintained during heat stress (Figure 2).

384 Other research suggests heating increases arousal, and thus maintains reaction time and attention, 385 until a critical $\mathrm{T}_{\mathrm{C}}$ is reached where impairments occur, which our participants were well below 386 (Hancock et al. 2003). Participants in our study also reported difficulty concentrating ( $\sim 33 \%$ 387 increase in concentration) during hyperthermia. However, attention, as measured by reaction time 388 and motor processing speed was not impaired. Difficulty concentrating could impair the ability to 389 form long-term memories and affect the learning ability of young females during heat stress. 390 Therefore, cognitive impairments seen with hyperthermia in this study could be influenced by both 391 heat-associated physiological responses, and distractions formed from increased symptoms and a 392 negative mood state.

\section{Influence of hypohydration on responses to hyperthermia}


Although some cognitive performance variables were impaired during hyperthermia, they

395

396

397

398

399

400

401

402

403

404

405

406

407

408

409

410

411

412

413

414

415

were not impaired to a greater degree when mild hypohydration occurred. Given that our sample

was young and healthy, physiological mechanisms could compensate in order to stabilize variables

after a certain amount of stress. Previous research has suggested that a longer period of hypohydration (60-h of fluid restriction) in young individuals did not exacerbate impairments seen at lower levels of hypohydration, but instead young individuals were able to maintain cognitive performance (Szinnai, Schachinger et al. 2005). Other models of inducing hypohydration, such as diuretics or exercise, may be necessary to investigate if a greater degree of hypohydration affects responses to hyperthermia.

\section{Influence of obesity}

Interestingly, there was no effect of body composition on cognitive performance, mood, or presentation of any symptoms. However, mental task load, in many areas, was significantly affected in the obese, but not the non-obese participants during hyperthermia. This indicates that obese individuals had a perception that the heat was imposing a great demand upon them. There is some evidence that autonomic dysfunction associated with obesity increases fatigue development in obese adults during periods of high mental stress (Mehta 2015). In particular it is concerning that decrements in physical performance occur much quicker in obese adults during periods of high mental stress (Mehta 2015). The stress of hyperthermia was not sufficient to impair cognitive performance, symptoms, or mood with moderate heating any more than it did for nonobese participants. The obese individuals did experience increased cardiovascular strain (as evidence by increased HR in this study), but the ability to maintain cerebral perfusion during cognitive task between groups is probably unaffected (Bar-Or, Lundegren et al. 1969). In 
416 summary, it is worth noting that performance is maintained in obese individuals, but they find it

417 harder to perform cognitive tasks while in the heat.

418 Limitations

Mood score only reflected negative feelings and did not give an overall mood state, which

420 may reduce our ability to fully interpret the overall mood state of the females. Also, mood

421 assessment occurred after instrumentation with the rectal probe which may negatively affect mood

422 state. Furthermore, the cognitive assessment (ImPACT) used was a series of five modules. The

423 modules are always administered in the same order for each test. Thus, the cognitive domains

424 measured were not counterbalanced. The lack of counterbalancing could indicate impairment to

425 one domain might affect a later module and the corresponding domain. However, given the

426 conditions of the experiment were counterbalanced, we are confident in our ability to examine the

427 effect of hydration and hyperthermia status on the measured variables. Additionally, we recognize

428 impairment to attention might impair latter modules. Although, most studies using heat stress

429 indicate attention is preserved, studies using hypohydration suggest attention might deteriorate.

430 Furthermore, since we were using a controlled passive heating protocol involving a water-

431 perfusion suit, heat was administered to the skin first and subsequently caused an increase in $\mathrm{T}_{\mathrm{C}}$.

432 The extension that this form of hyperthermia results in changes in cognition relies on the

433 assumption that changes in $\mathrm{T}_{\mathrm{C}}$ (in this case rectal) reflect changes in brain temperature (Covaciu

434 et al. 2011). The water-perfusion suits in this study do create an unnatural hyperthermic

435 environment surrounding the skin with $49^{\circ} \mathrm{C}$ water. This allows for rapid increases in $\mathrm{T}_{\mathrm{SK}}$ and $\mathrm{T}_{\mathrm{C}}$,

436 but limits external validity because such an extreme environment is unlikely to exist in an

437 occupational setting. Also, a number of other factors occur during exercise or physical labor, such

438 as blood flow demands and heat production at the muscle that may influence the cognitive response 
439 to exertional heat stress. Therefore, these results may not be generalized to exertional 440 hyperthermia.

\section{Conclusions}

442 In this study, we demonstrated that apparently healthy adult females experience mild 443 cognitive impairments, specific to memory, during moderate hyperthermia $\left(+1.0^{\circ} \mathrm{C}\right.$ increase $\operatorname{inT}_{\mathrm{C}}$

444 ). These impairments are not worse in obese individuals nor were cognitive impairments worsened 445 when hypohydrated. Hypohydration did not affect any variable related to cognitive function, with 446 the exception of a trend in visual memory. Impairments in mood, evidenced by increased fatigue 447 and depression, and mental task load accompanied cognitive impairments during hyperthermia. 448 Obese individuals experienced a greater demand of the mental activities during hyperthermia, but 449 did not experience greater cognitive impairments. Overall, obese individuals may not experience 450 greater cognitive impairments during hyperthermia, but they likely have to put forth a greater effort 451 to maintain their cognitive abilities. Therefore, during periods of high heat stress, obese individuals 452 are unlikely to experience cognitive performance decrements despite exerting greater effort in 453 comparison to their lean peers. Future studies should seek to determine if physical tasks are equally 454 affected by hyperthermia and hypohydration in obese and non-obese adults. 


\section{Acknowledgements}

456 We would like to thank everyone at the Exercise Science Research Center for helping facilitate

457 this research. Further, we would like to thank Shari Witherspoon and J.D. Adams for their help 458 with the administrative work in the laboratory. Further, we would like to thank Melissa

459 Anderson, Megan Rosa-Caldwell, and Dr. Sean Mulvenon for their help reviewing this

460 manuscript and statistical analyses. 


\section{References}

463

464

465

466

467

468

469

470

471

472

473

474

475

476

477

478

479

480

481

482

483

484

485

486

487

Adam, G.E., Carter, R., 3rd, Cheuvront, S.N., Merullo, D.J., Castellani, J.W., Lieberman, H.R., andSawka, M.N. (2008). Hydration effects on cognitive performance during military tasks in temperate and cold environments. Physiol Behav 93: 748-56.

Amos, D., Hansen, R., Lau, W.M., andMichalski, J.T. (2000). Physiological and cognitive performance of soldiers conducting routine patrol and reconnaissance operations in the tropics. Mil Med 165: 961-6.

Armstrong, L. (2007). Assessing hydration status: the elusive gold standard. Journal of the American College of Nutrition 26: 575S-584S.

Armstrong, L.E., Ganio, M.S., Casa, D.J., Lee, E.C., McDermott, B.P., Klau, J.F., Jimenez, L., Le Bellego, L., Chevillotte, E., andLieberman, H.R. (2012). Mild dehydration affects mood in healthy young women. J Nutr 142: 382-8.

Baars, B.J. (1993). How does a serial, integrated and very limited stream of consciousness emerge from a nervous system that is mostly unconscious, distributed, parallel and of. Experimental and theoretical studies of consciousness 98: 282.

Baddeley, A.D. and Hitch, G. (1974). Working memory. Psychology of learning and motivation 8: 47-89.

Bar-Or, O., Lundegren, H., andBuskirk, E. (1969). Heat tolerance of exercising obese and lean women. Journal of Applied Physiology 26: 403-409.

Bijur, P.E., Silver, W., andGallagher, E.J. (2001). Reliability of the visual analog scale for measurement of acute pain. Academic emergency medicine 8: 1153-1157.

Boeka, A.G. and Lokken, K.L. (2008). Neuropsychological performance of a clinical sample of extremely obese individuals. Arch Clin Neuropsychol 23: 467-74.

Buskirk, E., Bar-Or, O., andKollias, J. (1969). Physiological effects of heat and cold. Obesity. Philadelphia: Davis: 119-39. 
488 Cheuvront, S.N., Carter, R., 3rd, Montain, S.J., andSawka, M.N. (2004). Daily body mass

489

490

491

492

493

494

495

496

497

498

499

500

501

502

503

504

505

506

507

508

509

510

511

512

513

514

515

variability and stability in active men undergoing exercise-heat stress. Int J Sport Nutr Exerc Metab 14: 532-40.

Cian, C., Koulmann, N., Barraud, P.A., Raphel, C., Jimenez, C., andMelin, B. (2000). Influence of variations in body hydration on cognitive function: effect of hyperhydration, heat stress, and exercise-induced dehydration. Journal of Psychophysiology 14: 29-36.

Cohen, S.K., T; Mermelstein, R (1983). A Global Measure of Perceived Stress. Journal of Health and Social Behavior 24: 385-396.

Covaciu, L., Weis, J., Bengtsson, C., Allers, M., Lunderquist, A., Ahlstrom, H., andRubertsson, S. (2011). Brain temperature in volunteers subjected to intranasal cooling. Intensive Care Med 37: $1277-84$.

Fedor, A. and Gunstad, J. (2013). Higher BMI is associated with reduced cognitive performance in division I athletes. Obes Facts 6: 185-92.

Gallagher, D., Heymsfield, S.B., Heo, M., Jebb, S.A., Murgatroyd, P.R., andSakamoto, Y. (2000). Healthy percentage body fat ranges: an approach for developing guidelines based on body mass index. Am J Clin Nutr 72: 694-701.

Ganio, M.S., Armstrong, L.E., Casa, D.J., McDermott, B.P., Lee, E.C., Yamamoto, L.M., Marzano, S., Lopez, R.M., Jimenez, L., Le Bellego, L., Chevillotte, E., andLieberman, H.R. (2011). Mild dehydration impairs cognitive performance and mood of men. Br J Nutr 106: 1535-43.

Gaoua, N., Grantham, J., El Massioui, F., Girard, O., andRacinais, S. (2011a). Cognitive decrements do not follow neuromuscular alterations during passive heat exposure. International Journal of Hyperthermia 27: 10-19.

Gaoua, N., Racinais, S., Grantham, J., andEl Massioui, F. (2011b). Alterations in cognitive performance during passive hyperthermia are task dependent. Int J Hyperthermia 27: 1-9.

Grego, F., Vallier, J.M., Collardeau, M., Rousseu, C., Cremieux, J., andBrisswalter, J. (2005). Influence of exercise duration and hydration status on cognitive function during prolonged cycling exercise. Int J Sports Med 26: 27-33. 
516 Gunstad, J., Paul, R.H., Cohen, R.A., Tate, D.F., andGordon, E. (2006). Obesity is associated

517 with memory deficits in young and middle-aged adults. Eat Weight Disord 11: e15-9.

518 Gunstad, J., Paul, R.H., Cohen, R.A., Tate, D.F., Spitznagel, M.B., andGordon, E. (2007).

519 Elevated body mass index is associated with executive dysfunction in otherwise healthy adults.

520 Compr Psychiatry 48: 57-61.

521 Hancock, P.A. and Vasmatzidis, I. (2003). Effects of heat stress on cognitive performance: the 522 current state of knowledge. Int J Hyperthermia 19: 355-72.

523 Hart, S.G. and Staveland, L.E. (1988). Development of NASA-TLX (Task Load Index): Results 524 of empirical and theoretical research. Advances in psychology 52: 139-183.

525 Hocking, C., Silberstein, R.B., Lau, W.M., Stough, C., andRoberts, W. (2001). Evaluation of

526 cognitive performance in the heat by functional brain imaging and psychometric testing.

527 Comparative Biochemistry and Physiology Part A: Molecular \& Integrative Physiology

528 128: 719-734.

529 Kempton, M.J., Ettinger, U., Foster, R., Williams, S.C., Calvert, G.A., Hampshire, A., Zelaya, 530 F.O., O'Gorman, R.L., McMorris, T., Owen, A.M., andSmith, M.S. (2011). Dehydration affects 531 brain structure and function in healthy adolescents. Hum Brain Mapp 32: 71-9.

532 Lindseth, P.D., Lindseth, G.N., Petros, T.V., Jensen, W.C., andCaspers, J. (2013). Effects of 533 hydration on cognitive function of pilots. Mil Med 178: 792-8.

534 Lokken, K.L., Boeka, A.G., Austin, H.M., Gunstad, J., andHarmon, C.M. (2009). Evidence of 535 executive dysfunction in extremely obese adolescents: a pilot study. Surg Obes Relat Dis 5:

$536 \quad 547-52$.

537 Lokken, K.L., Boeka, A.G., Yellumahanthi, K., Wesley, M., andClements, R.H. (2010).

538 Cognitive performance of morbidly obese patients seeking bariatric surgery. Am Surg 76: 55-9.

539 Mehta, R.K. (2015). Impacts of obesity and stress on neuromuscular fatigue development and

540 associated heart rate variability. Int J Obes (Lond) 39: 208-13.

541 Moyen, N.E., Burchfield, J.M., Butts, C.L., Glenn, J.M., Tucker, M.A., Treece, K., Smith, A.J., 542 McDermott, B.P., andGanio, M.S. (2016). Effects of obesity and mild hypohydration on local 543 sweating and cutaneous vascular responses during passive heat stress in females. Appl Physiol 544 Nutr Metab 41: 879-87. 
545 Ogden, C.L., Carroll, M.D., Fryar, C.D., andFlegal, K.M. (2015). Prevalence of obesity among 546 adults and youth: United States, 2011-2014: US Department of Health and Human Services, 547 Centers for Disease Control and Prevention, National Center for Health Statistics.

548

549

550

551

552

553

554

555

556

557

558

559

560

561

562

563

564

565

566

567

568

569

570

571

572

573

Patel, A.V., Mihalik, J.P., Notebaert, A.J., Guskiewicz, K.M., andPrentice, W.E. (2007). Neuropsychological performance, postural stability, and symptoms after dehydration. Journal of athletic training 42: 66 .

Petri, N.M., Dropulic, N., andKardum, G. (2006). Effects of voluntary fluid intake deprivation on mental and psychomotor performance. Croat Med J 47: 855-61.

Pross, N., Demazieres, A., Girard, N., Barnouin, R., Santoro, F., Chevillotte, E., Klein, A., andLe Bellego, L. (2013). Influence of progressive fluid restriction on mood and physiological markers of dehydration in women. Br J Nutr 109: 313-21.

Racinais, S., Gaoua, N., andGrantham, J. (2008). Hyperthermia impairs short-term memory and peripheral motor drive transmission. J Physiol 586: 4751-62.

Ramanathan, N. (1964). A new weighting system for mean surface temperature of the human body. Journal of applied physiology 19: 531-533.

Sawka, M.N., Burke, L.M., Eichner, E.R., Maughan, R.J., Montain, S.J., andStachenfeld, N.S. (2007). American College of Sports Medicine position stand. Exercise and fluid replacement. Medicine and science in sports and exercise 39: 377-390.

Schatz, P., Pardini, J.E., Lovell, M.R., Collins, M.W., andPodell, K. (2006). Sensitivity and specificity of the ImPACT Test Battery for concussion in athletes. Arch Clin Neuropsychol 21: 91-9.

Schlader, Z.J., Gagnon, D., Adams, A., Rivas, E., Cullum, C.M., Crandall, C.G., andCrandall, C.G. (2015). Cognitive and perceptual responses during passive heat stress in younger and older adults. American Journal of Physiology-Regulatory, Integrative and Comparative Physiology: ajpregu. 00010.2015.

Schlader, Z.J., Lucas, R.A., Pearson, J., andCrandall, C.G. (2013). Hyperthermia does not alter the increase in cerebral perfusion during cognitive activation. Experimental physiology 98 : 1597-1607.

Shirreffs, S.M. (2003). Markers of hydration status. Eur J Clin Nutr 57 Suppl 2: S6-9. 
574 Simmons, S.E., Saxby, B.K., McGlone, F.P., andJones, D.A. (2008). The effect of passive 575 heating and head cooling on perception, cardiovascular function and cognitive performance in 576 the heat. European journal of applied physiology 104: 271-280.

577 Smith, M.F., Newell, A.J., andBaker, M.R. (2012). Effect of acute mild dehydration on 578 cognitive-motor performance in golf. J Strength Cond Res 26: 3075-80.

579

580

581

582

583

584

585

586

587

588

589

590

591

592

593

594

595

596

597

598

599

600

Stanek, K.M., Grieve, S.M., Brickman, A.M., Korgaonkar, M.S., Paul, R.H., Cohen, R.A., andGunstad, J.J. (2011). Obesity is associated with reduced white matter integrity in otherwise healthy adults. Obesity (Silver Spring) 19: 500-4.

Suhr, J.A., Patterson, S.M., Austin, A.W., andHeffner, K.L. (2010). The relation of hydration status to declarative memory and working memory in older adults. J Nutr Health Aging 14: 840-3.

Szinnai, G., Schachinger, H., Arnaud, M.J., Linder, L., andKeller, U. (2005). Effect of water deprivation on cognitive-motor performance in healthy men and women. Am J Physiol Regul Integr Comp Physiol 289: R275-80.

Terry, P.C., Lane, A.M., Lane, H.J., andKeohane, L. (1999). Development and validation of a mood measure for adolescents. Journal of Sports Sciences 17: 861-872.

Tomporowski, P.D., Beasman, K., Ganio, M.S., andCureton, K. (2007). Effects of dehydration and fluid ingestion on cognition. Int J Sports Med 28: 891-6.

Tucker, M.A., Butts, C.L., Satterfield, A.Z., Six, A., Johnson, E.C., andGanio, M.S. (2018). Spot Sample Urine Specific Gravity Does Not Accurately Represent Small Decreases in Plasma Volume in Resting Healthy Males. J Am Coll Nutr 37: 17-23.

Tucker, M.A., Caldwell, A.R., Butts, C.L., Robinson, F.B., Reynebeau, H.C., Kavouras, S.A., McDermott, B.P., Washington, T.A., Turner, R.C., andGanio, M.S. (2017). Effect of hypohydration on thermoregulatory responses in men with low and high body fat exercising in the heat. J Appl Physiol (1985) 122: 142-152.

Wilson, M.M. and Morley, J.E. (2003). Impaired cognitive function and mental performance in mild dehydration. Eur J Clin Nutr 57 Suppl 2: S24-9. 
601 Wolf, P.A., Beiser, A., Elias, M.F., Au, R., Vasan, R.S., andSeshadri, S. (2007). Relation of 602 obesity to cognitive function: importance of central obesity and synergistic influence of 603 concomitant hypertension. The Framingham Heart Study. Curr Alzheimer Res 4: 111-6.

604 Wyon, D.P., Andersen, I., andLundqvist, G.R. (1979). The effects of moderate heat stress on 605 mental performance. Scand J Work Environ Health 5: 352-61.

606

607 


\section{Table 1 (on next page)}

Demographic data from both the obese and non-obese groups. 


\begin{tabular}{ccc}
\hline \multicolumn{3}{c}{ Table 1. M \pm SD demographic data for non-obese and obese } \\
\hline Non-Obese & Obese \\
\hline Age (y) & 11 & 10 \\
Height (cm) & $165 \pm 5.8$ & $22 \pm 2$ \\
Mass (kg) & $60.56 \pm 5.76$ & $79.79 \pm 17.69^{*}$ \\
Body Fat (\%) & $25.13 \pm 3.93$ & $44.24 \pm 5.08^{*}$ \\
\hline
\end{tabular}

*Significantly different between groups $(\mathrm{p}<0.05)$

1 


\section{Table 2 (on next page)}

Hydration data collected pre- and post-heating while euhydrated and dehydrated in obese and non-obese individuals. 
Table 2. Hydration Markers

Body Mass Loss (kg) from 3-

Non-Obese

Obese

day Euhydrated Baseline

$\begin{array}{llrllll}\text { Pre-heating } & \text { Euhydrated } & 0.62 & \pm 1.08 & -0.44 & \pm 1.39 \\ & \text { Hypohydrated } & -0.97 & \pm 0.74^{\mathrm{b}} & -0.91 & \pm 0.90^{\mathrm{b}}\end{array}$

Body Mass Loss $(\mathrm{kg})$ after

passive heating

$\begin{array}{llllllll}\text { Post-heating } & \text { Euhydrated } & -0.89 & \pm & 0.43 & -0.23 & \pm & 0.24 \\ & \text { Hypohydrated } & -1.46 & \pm & 0.29^{\mathrm{b}} & -0.78 & \pm & 0.37^{\mathrm{b}}\end{array}$

Urine Specific Gravity

$\begin{array}{clllll}\text { Pre-heating } & \text { Euhydrated } & 1.008 & \pm 0.005 & 1.009 & \pm 0.006 \\ & \text { Hypohydrated } & 1.024 & \pm 0.004^{\mathrm{b}} & 1.026 & \pm 0.004^{\mathrm{b}} \\ & & & & & \\ \text { Post-heating } & \begin{array}{l}\text { Euhydrated } \\ \text { Hypohydrated }\end{array} & 1.009 \pm 0.003 & 1.011 \pm 0.007 \\ & 1.026 \pm 1.004^{\mathrm{a}, \mathrm{b}} & 1.029 \pm 0.004^{\mathrm{a}, \mathrm{b}}\end{array}$

Urine Osmolality (mOsm)

$\begin{array}{llrlrl}\text { Pre-heating } & \text { Euhydrated } & 347 & \pm 195 & 377 & \pm 226 \\ & \text { Hypohydrated } & 961 & \pm 105^{\mathrm{b}} & 1051 & \pm 116^{\mathrm{b}} \\ & & & & & \\ \text { Post-heating } & \text { Euhydrated } & 401 & \pm 104 & 454 & \pm 271 \\ & \text { Hypohydrated } & 992 & \pm 89^{\mathrm{a}, \mathrm{b}} & 1126 & \pm 114^{\mathrm{a}, \mathrm{b}}\end{array}$

Serum Osmolality (mOsm)

\begin{tabular}{cllll} 
Pre-heating & Euhydrated & 285 & \pm 2 & $283 \pm 3$ \\
& Hypohydrated & 289 & $\pm 4^{\mathrm{b}}$ & $287 \pm 3^{\mathrm{b}}$ \\
& & & & \\
Post-heating & Euhydrated & 284 & \pm 3 & $281 \pm 2$ \\
& Hypohydrated & $294 \pm 4^{\mathrm{a}, \mathrm{b}}$ & $291 \pm 3^{\mathrm{a}, \mathrm{b}}$ \\
\hline
\end{tabular}

${ }^{a}$ Significant difference from corresponding pre-heating value ${ }^{b}$ Significant difference from corresponding euhydration value

1 


\section{Table 3(on next page)}

Physiological data collected pre- and post-heating while euhydrated and dehydrated in obese and non-obese individuals. 
Table 3. Physiological Markers

Rectal Temperature $\left({ }^{\circ} \mathrm{C}\right)$

Non-Obese

Obese

$\begin{array}{clrlllll}\text { Pre-heating } & \text { Euhydrated } & 36.77 & \pm & 0.28 & 36.78 & \pm & 0.41 \\ & \text { Hypohydrated } & 36.83 & \pm & 0.24 & 36.87 & \pm & 0.43 \\ \text { Post-heating } & \text { Euhydrated } & & & & & & \\ & \text { Hypohydrated } & 37.72 & \pm & 0.26^{\mathrm{a}} & 37.76 & \pm & 0.39^{\mathrm{a}} \\ & 37.82 & \pm & 0.24^{\mathrm{a}} & 37.85 & \pm & 0.44^{\mathrm{a}}\end{array}$

Skin Temperature $\left({ }^{\circ} \mathrm{C}\right)$

\begin{tabular}{clllllll} 
Pre-heating & Euhydrated & 35.10 & \pm & 0.51 & 34.97 & \pm 0.45 \\
& Hypohydrated & 35.37 & \pm & 0.33 & 35.43 & \pm & 0.58 \\
\multirow{4}{*}{ Post-heating } & Euhydrated & 37.62 & \pm & $0.68^{\mathrm{a}}$ & 37.75 & \pm & $0.77^{\mathrm{a}}$ \\
& Hypohydrated & 37.90 & \pm & $0.62^{\mathrm{a}, \mathrm{b}}$ & 38.27 & \pm & $0.80^{\mathrm{a}, \mathrm{b}}$
\end{tabular}

Mean Body Temperature $\left({ }^{\circ} \mathrm{C}\right)$

$\begin{array}{llrlllll}\text { Pre-heating } & \text { Euhydrated } & 36.60 & \pm 0.26 & 36.60 & \pm 0.39 \\ & \text { Hypohydrated } & 36.80 & \pm 0.23 & 36.72 & \pm 0.42 \\ \text { Post-heating } & & & & & & \\ & \text { Euhydrated } & 37.71 & \pm & 0.27^{\mathrm{a}} & 37.76 & \pm 0.41^{\mathrm{a}} \\ & \text { Hypohydrated } & 37.83 & \pm 0.24^{\mathrm{a}, \mathrm{b}} & 37.90 & \pm 0.44^{\mathrm{a}, \mathrm{b}}\end{array}$

Heart Rate (bpm)

\begin{tabular}{clrrrrr} 
Pre-heating & Euhydrated & 64 & \pm 5 & $70 \pm 11^{\mathrm{c}}$ \\
& Hypohydrated & $65 \pm 8$ & $75 \pm 10^{\mathrm{c}}$ \\
\multirow{2}{*}{ Post-heating } & & & & & & \\
& Euhydrated & 94 & \pm & $8^{\mathrm{a}}$ & 104 & $\pm 14^{\mathrm{a}, \mathrm{c}}$ \\
& Hypohydrated & 98 & $\pm 8^{\mathrm{a}}$ & $106 \pm 11^{\mathrm{a}, \mathrm{c}}$
\end{tabular}

${ }^{a}$ Significant difference from corresponding pre-heating value ${ }^{\mathrm{b}}$ Significant difference from corresponding euhydration value. ${ }^{c}$ Significant difference from corresponding non-obese value 


\section{Figure 1}

Schematic of experimental design.

Data collection began with 3 days of euhydrated body weights (blue box, far left) collected every morning upon waking. In the 24-h prior to each trial participants either were assigned a fluid prescription protocol or withheld from fluid intake (black boxes, middle left). Upon arriving to the lab on testing day, participants underwent baseline testing (Black stars within experimental trial box, far left). Passive heating immediately began upon completion of baseline testing. Once a $1.0^{\circ} \mathrm{C}$ increase in rectal temperature was reached post testing began (Black stars within experimental trial box, far right). Participants were removed from the environmental chamber after post testing was completed. The black stars represent when measures for perception mood (Brunel Mood Scale; BRUMS), mental task load (NASATLX), and cognitive performance (ImPACT) occurred. 


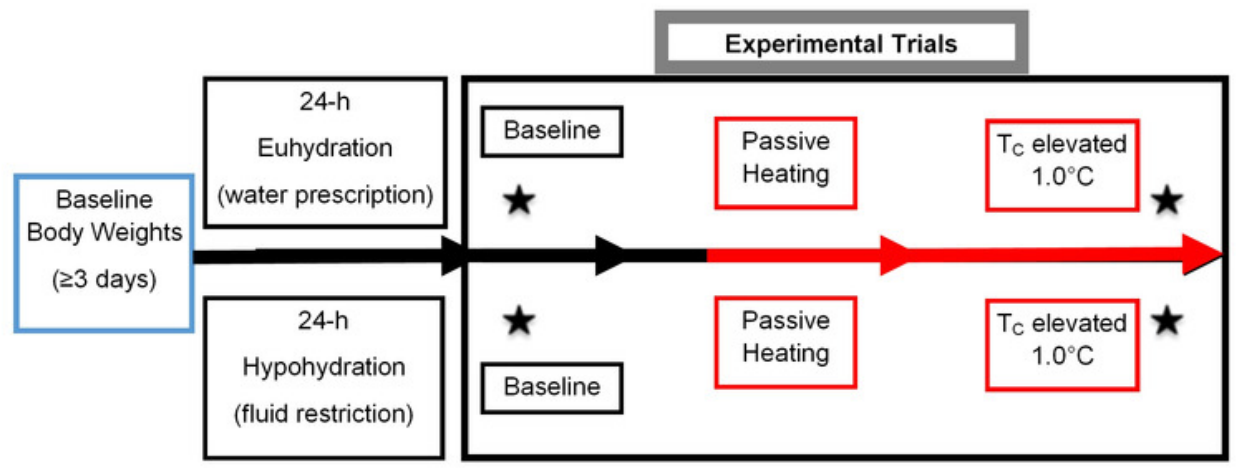




\section{Figure 2}

Cognitive Performance

(A) Cognitive performance variables (y-axis) from the ImPACT at baseline and during hyperthermia. Below are $(B)$ reaction time $(C)$ visual motor performance, $(D)$ visual memory, and (E) verbal memory from the ImPACT for each group (obese and non-obese) at baseline and during hyperthermia. *Indicates significant difference from baseline $(p<0.05)$, "Indicates a trend for a difference between baseline $(p<0.10)$. Symbols are vertically offset for clarity. 

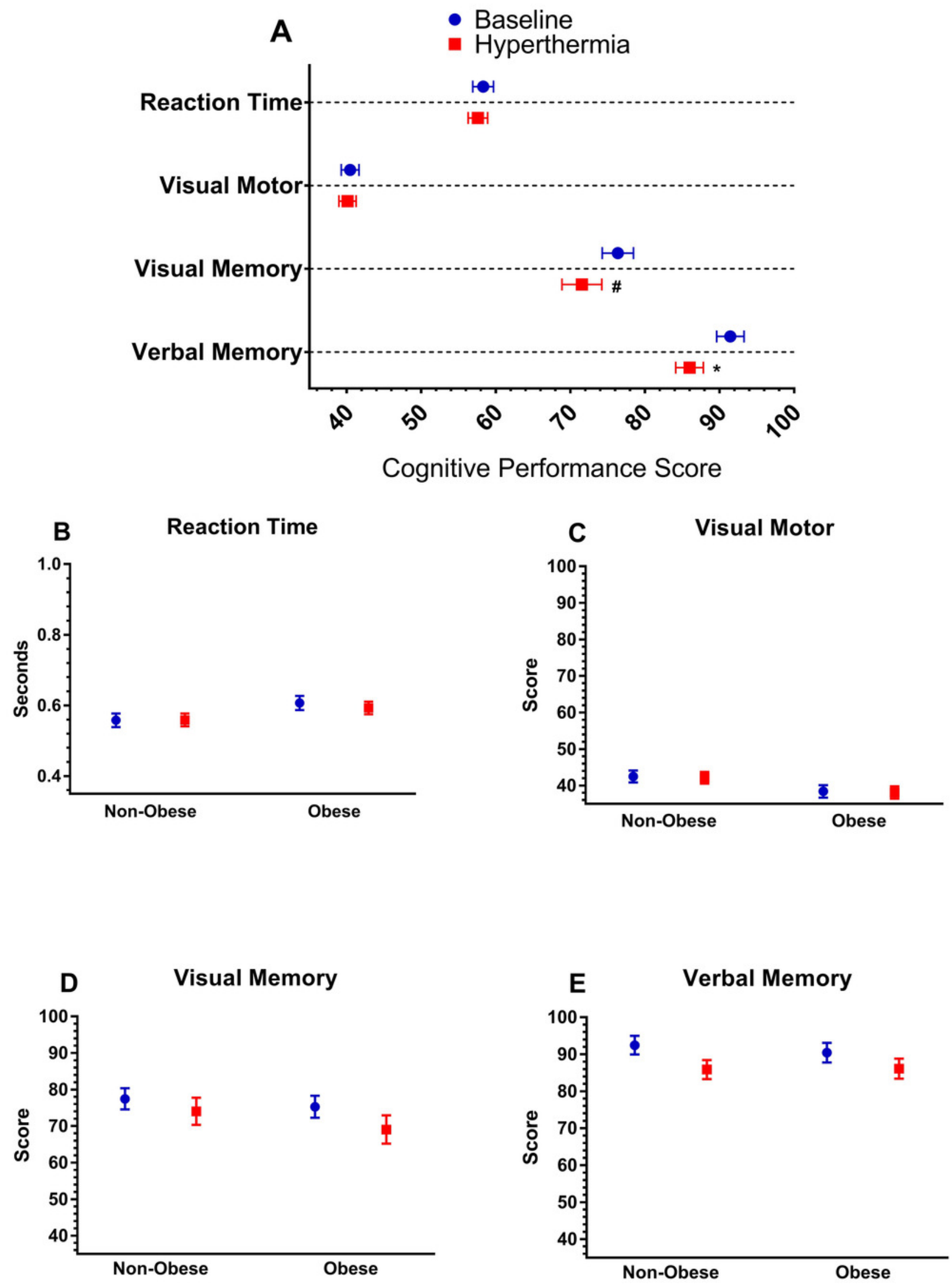


\section{Figure 3}

\section{Mental Task Load}

Perceived mental task load (NASA-TLX, visual analog score in arbitrary units) for (A) mental demand, (B) temporal demand (C) performance, (D) frustration, $(E)$ effort, and (F) concentration for each group (obese and non-obese) at baseline and during hyperthermia *Indicates significant difference from baseline within group $(p<0.05)$. 

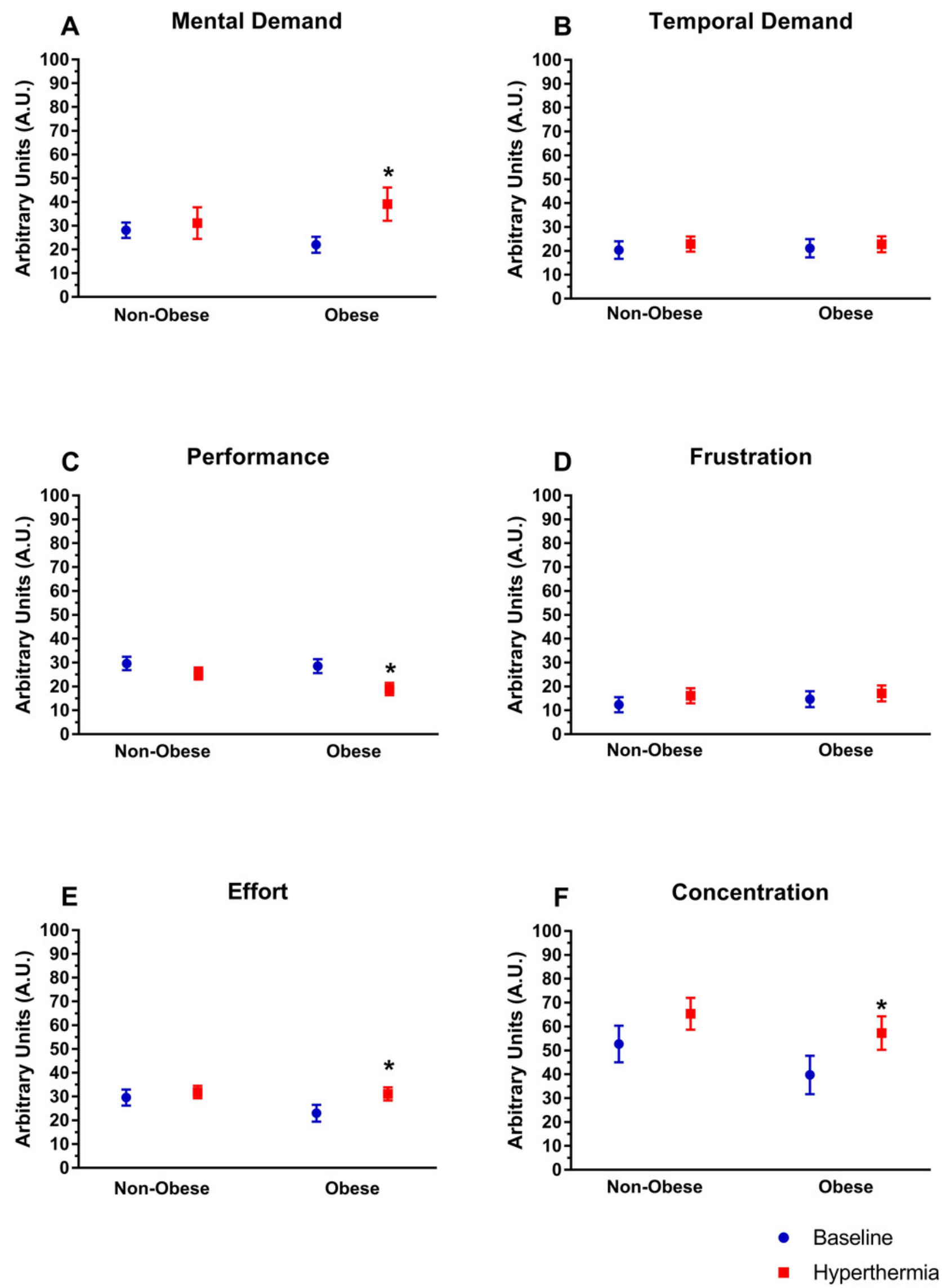


\section{Figure 4}

Mood state scores from the Brunel Mood Scale

(A) Perceived mood state scores (in arbitrary units) from the Brunel Mood Scale (BRUMS) compared at baseline and during hyperthermia. To the right are the mood responses split by group (obese versus non-obese) including (B) tension, (C) depression, (D) anger, (E) vigor, (F) fatigue, and $(G)$ confusion.*Indicates significant difference from baseline $(p<0.05)$, "Indicates a trend for a difference between baseline $(p<0.10)$.
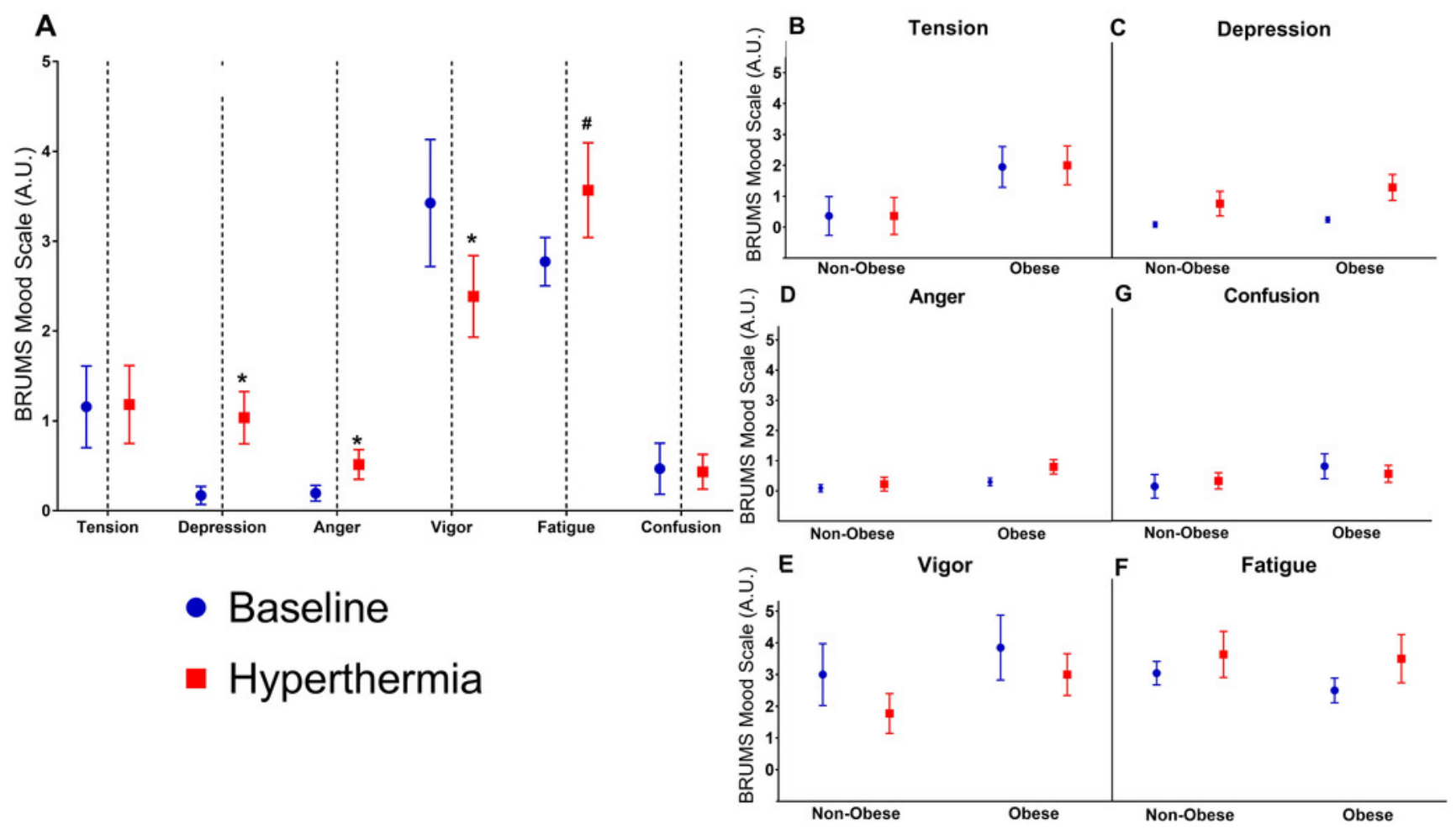